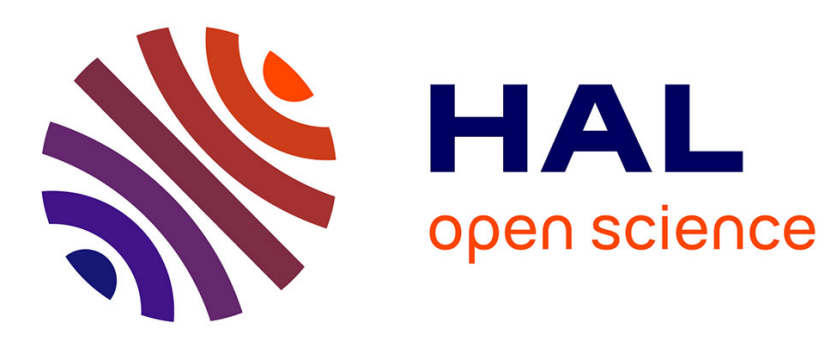

\title{
Synthesis, Evaluation, and Selection of Parts Design Scheme in Supplier Involved Product Development
}

\author{
Jiafu Tang, Yan-E Zhang, Yiliu Tu, Yizeng Chen, Ying Dong
}

\section{To cite this version:}

Jiafu Tang, Yan-E Zhang, Yiliu Tu, Yizeng Chen, Ying Dong. Synthesis, Evaluation, and Selection of Parts Design Scheme in Supplier Involved Product Development. Concurrent Engineering: Research and Applications, 2005, 13 (4), pp.277-289. 10.1177/1063293X05059806 . hal-00571184

\section{HAL Id: hal-00571184 \\ https://hal.science/hal-00571184}

Submitted on 1 Mar 2011

HAL is a multi-disciplinary open access archive for the deposit and dissemination of scientific research documents, whether they are published or not. The documents may come from teaching and research institutions in France or abroad, or from public or private research centers.
L'archive ouverte pluridisciplinaire HAL, est destinée au dépôt et à la diffusion de documents scientifiques de niveau recherche, publiés ou non, émanant des établissements d'enseignement et de recherche français ou étrangers, des laboratoires publics ou privés. 


\title{
Synthesis, Evaluation, and Selection of Parts Design Scheme in Supplier Involved Product Development
}

\author{
Jiafu Tang, ${ }^{1, *}$ Yan-e Zhang, ${ }^{1}$ Yiliu Tu, ${ }^{2}$ Yizeng Chen ${ }^{3}$ and Ying Dong ${ }^{1}$ \\ ${ }^{1}$ Department of Systems Engineering, Key Laboratory of Process Industrial Automation of MOE, School of Information \\ Science \& Engineering, Northeastern University (NEU), Shenyang, 110004, P.R.China \\ ${ }^{2}$ Department of Mechanical and Manufacturing Engineering, University of Calgary, 2500 University Drive NW \\ Calgary, Alberta, T2N 1N4, Canada \\ ${ }^{3}$ Department of Industrial \& Systems Engineering, The Hong Kong Polytechnic University \\ Hung Hom, Kowloon, Hong Kong
}

\begin{abstract}
Taking into account the supplier involvement in the new product development (NPD), this article focuses on the synthesis evaluation, and selection of the part design scheme in part deployment process. The concepts of performance indicator $(\mathrm{Pl})$ and integrated performance indicators (IPI) are introduced to measure the performance of the part design scheme and product design scheme respectively. A two-layer fuzzy synthesis evaluation method is applied to assess the part design scheme in a supplier-involved new product development process. Combining the information of House of Quality ( $\mathrm{HoQ}$ ) and evaluation results of the part design scheme and taking into account the design budget, a $0-1$ integer programming model is developed for selection of the parts combinatorial scheme in supplier-involved part deployment processes. A case study with a type of liquid crystal display (LCD) design in an Electronic Appliance Manufacturing Enterprise is also illustrated in the article.
\end{abstract}

Key Words: QFD, part design scheme, synthesis evaluation, 0-1 integer programming, new product development (NPD)

\section{Introduction}

In the global market environment, the capacity to develop new products within a short time, with cheaper prices and better quality is becoming a key factor for the manufacturing enterprises to earn market competitiveness. New product development (NPD) is a complex information and business process, and it must therefore be managed efficiently and effectively as planning activity not only internally in a manufacturing company but also externally in its supply chain. Quality function deployment (QFD) is a well-known customer-oriented methodology for planning the quality of a product and controlling the product development processes from the conceptual design to manufacturing operations in response to the 'Voice of Customer' [1,20]. QFD provides a systematic approach to planning and managing the product development process effectively towards a new product with high customer satisfaction, good quality, short time-to-market, and at a cheap price $[15,21]$. The House of Quality (HoQ) of the QFD

*Author to whom correspondence should be addressed

E-mail: jftang@mail.neu.edu.cn

Figure 2 appears in color online: http://cer.sagepub.com provides an efficient means to transform customer requirements to engineering characteristics, then to part characteristics and technology characteristics, and finally to particular manufacturing operations. Since QFD was originally introduced in 1967 in Japan, many new concepts, particularly several versions of QFD, e.g., Fuzzy QFD, Extended QFD, Dynamic QFD and CFD have been developed and reported $[4,16,20,21]$. Particularly, Prasad [20] made a holistic review on development of QFD, extended QFD, and was the first one to propose the new concept of Concurrent Function Deployment (CFD). In his later article [21], the author further presents the framework and components of the CFD in detail. The CFD is developed particularly to manage workgroup based product design processes in a parallel deployment process of a number of values. With this methodology, a concurrent deployment process of the value sets including functionality, performance, tools and technology, cost, responsiveness, and infrastructure, rather than quality itself, is made. The perspective of value characteristics, artifact's value and requirements, and constraints are considered in the CFD methodology. The recent development on methodology, software tools and applications of QFD as well as the rest of the vast amount of literatures on the subject are summarized and reported by Chan [4]. 
The whole course of product development is divided into four processes: product planning, parts planning, technologic process planning, and manufacturing control planning. Much attention has been paid to product planning $[9,16,23,25,28,29]$, while fewer researches have been reported on the latter three planning processes [5,10]. In this aspect, Iranmanesh et al. [15] recently developed a two-phase based QFD to help design a team that would determine optimal design strategy in order to achieve higher customer satisfaction. The aforementioned models and approaches of QFD are mostly focused on the product development process in a company-wide scale rather than supply chain enterprises.

In an enterprise-wide product development process, the product design and development is carried out by a design team, whose members are normally from different functional departments in the scope of internal enterprises. It neglects the supplier's roles in part and process design, subcontracting, and production in a NPD process. The supplier's participation in a NPD process is limited to supplying parts and/or materials, and subsequently there exists a large gap between the requirement and specification of designed parts and that of the supplied parts [13]. Thus, without the supplier's involvement in the NPD process, the design and production of product parts are separated. This results in the supplier's information on the parts (e.g., specifications and performance, time availability, and the cost of parts) as well as the supplier's reputation and core design, and production capability being inaccessible to the design and manufacturing enterprise. Subsequently, it results in higher costs, longer time-to-market, and unreliable quality $[7,26]$.

With the advances in information technology and emergence of supply chain management, many enterprises are changing the ways they develop a new product. One apparent trend is to involve external business partners, particularly the suppliers, in their product development activities. Earlier supplier involvement (ESI) in NPD has become a popular means for improving product quality; reducing costs and compressing delivery lead time in a highly competitive global market [3,11,14,18,30,31]. For example, Bidault et al. [3] conducted an empirical study of ESI practices in twentyfive companies at the conceptual design stage of NPD, and suggested a model to guide ESI adoption. Holmenand and Kristensen [14] examined the supplier's role in NPD through task partitioning and points out the roles in the forms of design consultation, supply of components and parts, etc. LaBahn and Krapfel [17] proposed some hypotheses of positive influence on suppliers with ESI. Wynstra [30] listed four types of possible supply involvement and developed a portfolio approach to distinguish them. Maffinand and Braiden [18] applied comparative analysis and benchmarking to investigate the roles of manufacturer and supplier in NPD by interviewing 46 electrical and mechanical engineering companies in the UK. Toni and Nassimbeni [27] established a model framework for analyzing and evaluating the supplier's co-design in buyer's NPD activities. Ragatz et al. [22] developed a model for testing the effects of supplier integration on product quality, cost, and development lead time under technical uncertainties. Sobrero and Roberts [24] discussed the effects of conceptual and organizational relationship between suppliers and manufacturers on NPD. Caputo and Zirpoli [6] discussed the motivations, modalities, and consequences of supplier involvement in an automotive component design and presented exploratory multiple case studies on a major European car manufacturing enterprise and two of its suppliers. Huang et al. [11] proposed a prototype web-based framework for supporting and facilitating early supplier involvement in NPD on the Internet.

However, most of the current research on ESI in NPD is mainly restricted in the aspects of the forms, roles, and timing and the extent to which the supplier is involved in NPD; and some, in the aspects of the effects of supplier on quality, costs, and developing time in qualitative ways including comparative analysis, benchmarking analysis, interview survey, questionnaire, and case study. As an important issue in managing this involvement, the planning of design activity and the quantitative evaluation and assessment of effects of supplier on quality, cost, developing time, and customer satisfaction received little attention from researchers $[5,10,26]$. These issues should be addressed to improve NPD efficiency and customer satisfaction.

The quality and reliability of a product are predominantly determined in the early phase of the product development process. After determining a product functional structure during the product conceptual design process, the succeeding design procedure is product specifications, which is dominated by part deployment. In the part deployment phase, the designers not only need to determine the components or parts of the product, but also need to specify technical parameters of the components or parts under consideration of their functional and performance requirements. In general, each of the parts of a product has several alternative design solutions. Particularly, within supplier involvement in NPD, there are many suppliers. Each of these suppliers provides several alternative design solutions for a part. Thus, there are large volumes of combinatorial design schemes for a developing product. How to evaluate these schemes and select suitable ones are becoming important decision issues in the part deployment process.

This article focuses on the synthesis, evaluation, and selection of part design scheme in a part deployment process with part-supplier involvement. Taking into account the supplier involvement in the NPD, 
a two-layer fuzzy synthesis evaluation method is developed to evaluate the parts design scheme in supplier involved NPD process. This method utilizes the fuzzy sets theory to first evaluate the supplier, then assess the alternative solutions provided by part suppliers, and finally, to integrate the results of evaluation and obtain the performance indicator of the parts design scheme. Combining the information of $\mathrm{HoQ}$ and evaluation results of the part design scheme and taking into account the design budget, a $0-1$ integer programming model is developed for selection of parts combinatorial scheme (PCS) in supplier involved part deployment process. Distinguished from other approaches [15,21], this approach considers the involvement of parts suppliers during the conceptual design process and it combines the evaluation and optimization for part design scheme selection.

Following the introduction, formulation of HoQ and some notations are given in Section 2. The procedures of fuzzy synthesis evaluation of parts design scheme and selection of parts combinatorial design scheme are presented in detail in Sections 3 and 4 respectively, after introducing some new concepts. A case study with liquid crystal display (LCD) design in an electronic appliance manufacturing enterprise is introduced in Section 5, and the conclusions are finally given in Section 6 .

\section{Formulation of House of Quality}

With QFD, House of Quality (HoQ) provides an efficient tool to transform customer requirements hierarchically to engineering characteristics, parts characteristics, technologic characteristics, and particular manufacturing operations as shown in Figure 1. Thus, the whole QFD based product development process is divided into product planning, parts deployment planning, technologic process planning, and manufacturing control planning, each conducted by a HoQ $[1,12]$. The four HoQs have the same structure and components, even though their components may have different meanings.
In the first $\mathrm{HoQ}$, the left wall shows customer requirements (CRs) and its priority (weight), which describes what the customer wants for a product in the aspects of function, performances, feelings, appearance, and aesthetics. The backbone of the house gives engineering characteristics (ECs) expressed in technical and measurable terms, which represent technical means or designed product features to meet the customer's requirements. In general, there are various CRs for a product. Each can be translated into multiple ECs, and conversely a certain set of ECs may affect various CRs. Hence, there exist complex relationships between CRs and ECs. The relationship matrix is shown in the central room of the house. Also the ECs have correlations among themselves to formulate a correlation matrix that is shown in the top of the house. In the part deployment planning process, the engineering characteristics (ECs) are inputs of the second HoQ as 'what', and the parts characteristics are technical means to achieve the desired ECs. The components in the third and forth HoQs can be explained in a similar way.

Assuming a certain product has $n$ customer requirements (denoted by $\mathrm{CR}_{i}, i=1,2, \ldots, n$ ) and $m$ engineering characteristics (denoted by $\mathrm{EC}_{j}, j=1,2, \ldots, m$ ), the overall customer satisfaction can be gauged according to the extent to which individual customer requirements are fulfilled $[8,9,25,29]$. Let $A$ be the relationship matrix between CRs and ECs, each element $A_{i j}$, $(i=1,2, \ldots, n ; j=1,2, \ldots, m)$ indicates the relative strength of the $j$ th EC towards fulfilling the $i$ th CR. It can be quantified with a rating scale, such as $1-3-9$ or 1-9-15 to denote weak, medium, and strong relationships respectively. $A_{i j}^{*}$, the normalized $A_{i j}$ can be used to express the contribution of the $j$ th $\mathrm{EC}$ towards the fulfillment of the $i$ th CR when the target of the $j$ th $\mathrm{EC}$ is met. Let $r_{i}(i=1,2, \ldots, n)$ be the weight of the $i$ th $\mathrm{CR}$ to indicate the relative importance of the $i t h$ CR towards overall customer satisfaction. The value of $r_{i}$ can be determined by Analytical Hierarchical Process (AHP) [2]. Further let $u_{j}(j=1,2, \ldots, m)$ be the relative importance weight of the $j$ th EC. The vectors of $R$ and $U$ denote the weight vectors of

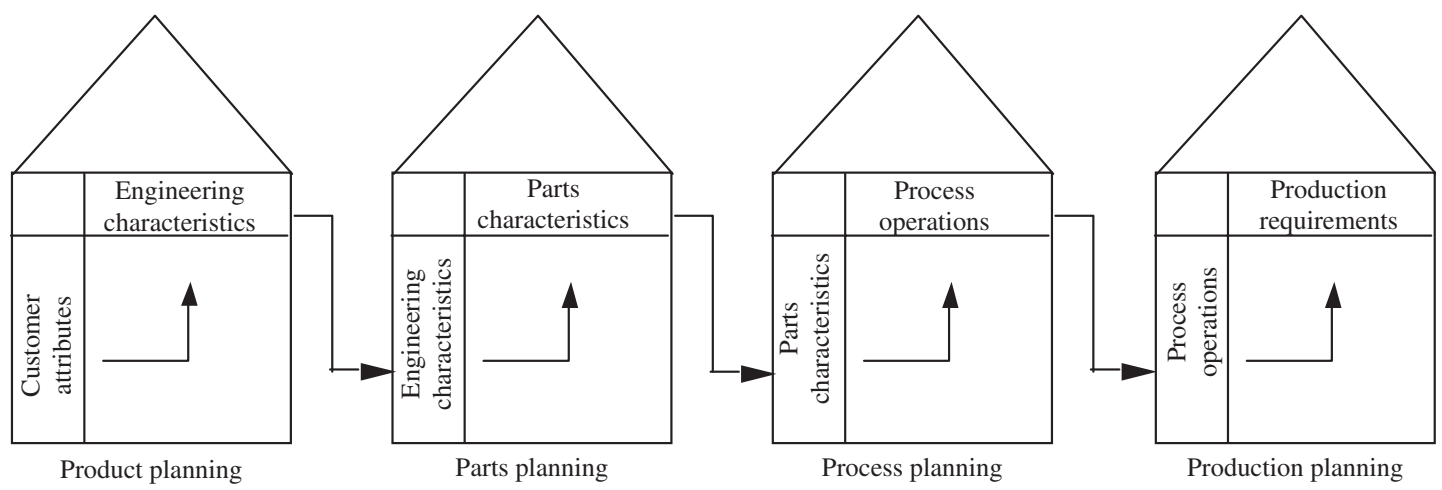

Figure 1. Working principle of QFD through using HoQ. 
customer requirements and of engineering characteristics respectively. The relationships between the weight of the CRs and the weight of ECs can be formulated as follows:

$$
u_{j}=\sum_{i=1}^{n} r_{i} A_{i j}^{*} \quad j=1,2, \ldots m, \quad A_{i j}^{*}=\frac{A_{i j}}{\sum_{k=1}^{m} A_{i k}}
$$

In a typical HoQ, the inter-dependence among the ECs is represented as the correlation matrix $T$. Each element $T_{j g}$ in $T$ denotes the degree of dependence of the $j$ th EC on the gth EC. These correlations can be quantified using a scale e.g., 1-3-5-9, where the values $1,3,5$ represent the degree of weak, medium, or strong dependency between two different ECs respectively, and 9 is used as the dependence of EC on itself. After normalization, $T_{j g} \in[-1,1] . T_{j g}>0$ indicates that the two ECs supplement each other, whereas $T_{j g}<0$ implies a conflict action between two ECs, i.e., two ECs have negative impacts upon each other. If there is no dependence between them, $T_{j g}=0$. The normalized correlation element $T_{j g}$ can be interpreted as incremental changes of the degree of attainment of the gth EC when the degree of attainment of the $j$ th $\mathrm{EC}$ is increased by one unit $[8,25]$. Taking into consideration the correlation among the ECs, the absolute weight vector of the ECs is updated from the formula (1) by:

$$
U=T A^{*^{T}} R
$$

After normalization, the relative weights of ECs can be given in terms of

$$
u_{j}^{*}=\frac{u_{j}}{\sum_{k=1}^{m} u_{k}}, \quad j=1,2, \ldots, m
$$

The formulation of the HoQ in the part deployment process can be conducted in a similar way. Assuming a certain product has $h$ parts (each denoted by PA), let $E$ be the relationship matrix between ECs and PAs (parts characteristics). The element $E_{j k}(j=1,2, \ldots, \mathrm{m}$; $k=1,2, \ldots, h)$ indicates the relative strength of the $k$ th PA towards fulfilling the $j$ th EC, and it can be quantified with a rating scale, such as $1-3-9$ or $1-9-15$ to denote weak, medium, and strong relationships respectively. Let $P$ be the correlation matrix among PAs; each element $P_{k s}$ denotes the degree of dependence of the $k$ th PA on the sth PA. If there is no dependence between them, $P_{k s}=0$; if a part has the strongest dependence on itself, $P_{k k}$ is given a maximum value. When $P_{k s}>0$, the two parts have a positive correlation between each other, whereas $P_{k s}<0$ implies a conflict of interest between the two parts. When $P$ is normalized, $P_{k s} \in[-1,1]$, and it can be interpreted as incremental changes of the degree of the attainment of the sth part when the degree of attainment of the $k$ th PA is increased by one unit. Taking into account the correlation among PAs, the absolute weight vector $V$ of parts is expressed as follows:

$$
V=P E^{*^{T}} U^{*}, \quad E_{j k}^{*}=\frac{E_{j k}}{\sum_{l=1}^{h} E_{j l}}
$$

After normalization, the relative weight of the $k$ th part can be given as:

$$
v_{k}^{*}=\frac{v_{k}}{\sum_{l=1}^{h} v_{l}}, \quad k=1,2, \ldots, h
$$

\section{Fuzzy Synthesis Evaluation of Parts Design Scheme with Supplier Involvement}

\subsection{Framework of Evaluation of Part Design Scheme}

After determining the functional structure of the product through the conceptual design process, the succeeding design process is called product specification design or the part deployment. In the part deployment phase, the designers not only need to determine the composed components or parts (simply referred to as parts hereafter) of the product, but also need to design technical solutions for all individual parts to meet the functional requirement [19]. In general, in the course of a part design, more than one alternative technical solution is provided, and they are evaluated and balanced from several aspects before a preferable one is determined finally. Under suppliers' involved in the NPD environment, the parts suppliers can utilize their core design ability and participate in the part design process, rather than the manufacturing process, so as to coincide with the part's performance requirements. The design and manufacturing enterprises may make the best use of supplier's enthusiasm for participation in parts design and subcontract the parts design tasks to them. Thus, taking into account suppliers' involvement in NPD, the evaluation and selection of the product design scheme becomes a very important task for manufacturing enterprises.

When suppliers are involved in part deployment process, there may be multiple suppliers bidding for an individual part design. Each may provide one or several options. The relationships among products, parts, suppliers, and technical solutions or schemes are sketched in a hierarchical model as shown in Figure 2. In the hierarchical model in Figure 2, the first layer is the product layer which consists of multiple components/ parts given in the second layer, followed by the supplier 


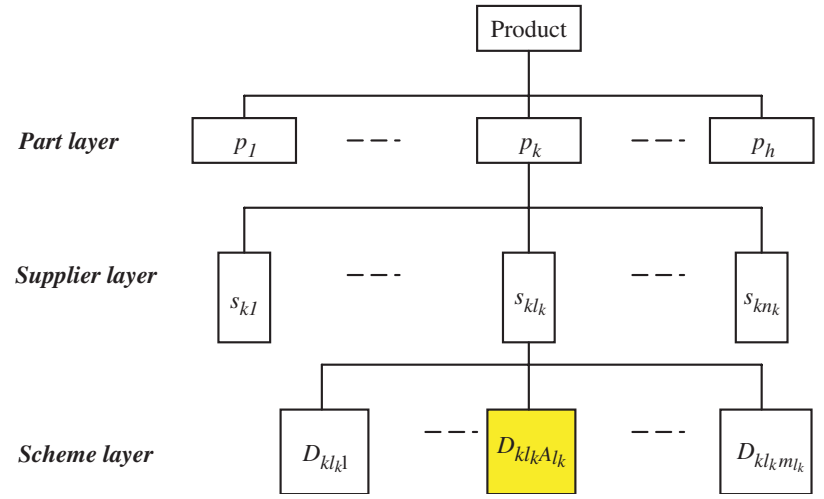

Figure 2. Hierarchical model of part, supplier, and alternative solution of part design.

layer, and finally, the solution layer at the bottom. For the sake of formulating synthesis and evaluation process in the following subsections, firstly, the concepts of alternative solution, design scheme, and selected scheme for a part and parts combinatorial scheme (PCS) are introduced here. Without consideration of supplier, an alternative solution is just a technical solution for a part design, while a design scheme is an alternative solution corresponding to a specified supplier. That is to say, evaluation of an alternative solution is just made from the technical solution of a part design itself, while evaluation of a design scheme should be made from the perspectives of both alternative solution and its supplier. A selected scheme for a part is a preferable one, selected from many design schemes provided by many suppliers after evaluation processes. A PCS is a product design scheme by which each part has a selected scheme. As indicated in Figure 2, the product is composed by $h$ parts; each is denoted by $p_{k}$, $k=1,2, \ldots, h$. For the $k$ th part $p_{k}$, there are $n_{k}$ suppliers to bid for the part design, each is denoted by $s_{l_{k}}$, $l_{k}=1,2, \ldots, n_{k}$. For the $k$ th part $p_{k}$, each of the alternative solutions of the part design is given as $A_{l_{k}}=1,2, \ldots, m_{l_{k}}$, and the corresponding design scheme from the supplier $l_{k}$ is denoted by $D_{k l_{k} A_{l_{k}}}$.

During the part deployment process, the overall process of evaluation and selection of a part design scheme is summarized in five steps as follows:

\subsubsection{PROCEDURE 1: OVERALL PROCESS OF EVALUATION AND SELECTION OF PART DESIGN}

Step 1: Announcing the information for calling bid for a part design.

Step 2: Evaluating the candidate suppliers separately and giving an evaluation grade to each supplier.

Step 3: All of the alternative solutions of the part provided by a supplier are evaluated and scaled in different grades, and each with a unique grade.

Step 4: Based on the grades of the evaluation of the supplier and its alternative solutions, the synthesis evaluation of each design scheme of a part is conducted and an aggregated grade is obtained with a mathematical operator.

Step 5: Based on the synthesis evaluation, a selected scheme for a part design is determined to be the design scheme with the best grade, and thus correspondingly the supplier and its solution are selected.

\subsection{Performance Measure of a Design Scheme}

In order to formulate the evaluation of alternative solution and design schemes of parts in a quantitative way, the concept of performance indicator (PI) is introduced in this section to measure the performance of the alternative solution and the design scheme of a part. The PI of an alternative solution of a part is obtained using fuzzy synthesis evaluation with multiple attributes and is denoted mathematically by $P I_{1}$. While the PI of a design scheme is quantified using fuzzy synthesis evaluation, not only from technical aspects of the part design, but also taking into account the evaluation grade of the part supplier, and hence it is achieved by aggregating the evaluation grade of the supplier and PI of the alternative solution. To distinguish from the PI of the alternation solution, the PI of a design scheme is symbolically denoted by $\mathrm{PI}_{2}$.

Let $g\left(l_{k}\right)$ and $P I_{1}\left(A_{l_{k}}\right)$ denote the evaluation grade of the supplier $l_{k}$ and the PI of its alternation solution $A_{l_{k}}$ respectively in the fuzzy synthesis evaluation process, and $P_{2}\left(D_{k l_{k} A_{l_{k}}}\right)$ denote the PI of the corresponding design scheme of the $k$ th part. The PI of a design scheme can be interpreted as the contribution level of the design scheme to overall customer satisfaction level of a certain product. In the following sub-sections, the fuzzy synthesis evaluation procedures for obtaining the evaluation grade of supplier and performance indicators of the alternative solution and part design scheme are discussed.

\subsection{Fuzzy Synthesis Evaluation of Suppliers}

As a method of multiple attribute decision analysis, fuzzy synthesis evaluation is based on fuzzy set theory to give an object an overall evaluation through taking into account multiple influencing factors. It is categorized into single-level and multi-level fuzzy synthesis evaluation according to the complexity of the evaluated objects.

There are four pivotal facets in the fuzzy synthesis evaluation, they are: (1) factor set, which is a set of attributes or factors that influence the object being evaluated; (2) weight set, an element of which indicates the relative importance of the influencing factors; (3) opinion set, that is a set of linguistic levels to scale the grade of the evaluated object; and (4) single factor evaluation, indicating the degree of membership of each attribute to each linguistic level in the opinion set. 
The single-level synthesis evaluation is adopted in this section to conduct the fuzzy synthesis evaluation of suppliers. The procedure is illustrated as follows with the example of the $l_{k}$ th supplier of the $k$ th part.

\subsubsection{PROCEDURE 2: FUZZY SYNTHESIS EVALUATION OF SUPPLIER}

Step 1: Determine the influencing factor set $\Omega=\left\{\pi_{k 1}, \pi_{k 2}, \ldots, \pi_{k f_{k}}\right\}$, each element of which represents a criteria or attribute for assessing the supplier, for example, part quality, part cost, core design ability, supply capacity, credit standing lever, response time, financial stability, and reputation. Thus,

$\Omega=\{$ cost, quality, response time, core design ability, supply capacity, reputation, financial stability, credit standing level\}.

Step 2: Determine opinion set of suppliers $\Theta=$ $\left\{\varepsilon_{k 1}, \varepsilon_{k 2}, \ldots, \varepsilon_{k g_{k}}\right\}$ to give evaluation classification of the suppliers. For instance, the supplier can be classified into five classes, such as World class (ideal), Award winners (reliable), Improvers (potential), Drifters (unfavorable), and Uncommitted (unqualified). To quantify the assessment of the supplier, a numerical value is given using a scaling method. For example, the scale values $1.0,0.8,0.6,0.4,0.2$ are assigned to the assessment of supplier with World class, Award winner, Improver, Drifters and Uncommitted respectively. Let $\alpha_{i}, i=1,2, \ldots, g_{k}$ be the numerical value of the evaluation class of suppliers by using a scaling method. Step 3: Determine the weight vector $W=$ $\left\{w_{k 1}, w_{k 2}, \ldots, w_{k f_{k}}\right\}$ of attributes so that $w_{k i} \geq 0$, $\sum_{i=1}^{f_{k}} w_{k i}=1$.

Step 4: Establish the assessment matrix. Each element of the matrix indicates the degree of membership of an attribute of the supplier to an evaluation class in opinion set. The assessment matrix is expressed in terms of a $f_{k} \times g_{k}$ matrix $O=\left(O_{k 1}, O_{k 2}, \ldots, O_{k g_{k}}\right)$, where $O_{k i}$ is a vector of number of $f_{k}$ elements, each represents the degree of membership of the supplier to the $i$ th class from the aspect of a specified attribute.

Step 5: Determine the fuzzy synthesis evaluation vector in terms of $B=W \times O$. The vector $B$ denotes the degree of membership of the supplier to each evaluation class with consideration of the multiple attributes.

Step 6: Determine the evaluation class of the supplier using the maximum degree of membership method or other methods. If the maximum membership degree method is accepted, the supplier is positioned at the evaluation grade with $b_{i}=\max \left(b_{j}\right)$ and assigned with a numerical value

$$
g_{k}\left(l_{k}\right)=\alpha_{i}
$$

\subsection{Fuzzy Synthesis Evaluation of Alternative Solutions}

When evaluating an alternative solution of a part design by means of fuzzy synthesis evaluation, a large number of attributes should be considered, and these attributes span different aspects of part characteristics, and hence can be further divided into several subclasses; thus multi-level fuzzy synthesis evaluation is carried out in this subsection. It is illustrated with the example of an alternative solution $A_{l_{k}}$ from the supplier $l_{k}$.

\subsubsection{PROCEDURE 3: FUZZY SYNTHESIS EVALUATION OF AN ALTERNATIVE SOLUTION}

Step 1: Determine the factors that influence the assessment of the alternative solution and denote the factors set by $\Omega$. These factors are further divided into $s$ subclasses, each is denoted by $\Omega_{i}=\left\{\sigma_{i 1}, \sigma_{i 2}, \ldots, \sigma_{i n_{i}}\right\}$ $(i=1,2, \ldots, s)$ such that $\sum_{i=1}^{s} n_{i}=n \bigcup_{i=1}^{s} \Omega_{i}=\Omega$; $\Omega_{i} \bigcap \Omega_{j}=\oslash, i \neq j$. The factors subclass $\Omega_{i}$ reflects certain engineering characteristics of part $p_{k}$, thus their relative importance can be obtained by engineers. Let $w_{i}$ denote the weight of subclass $\Omega_{i}(i=1,2, \ldots, s)$ and $W=\left(w_{1}, w_{2}, \ldots, w_{i}, \ldots, w_{s}\right)$ be the weight vector of factor subclasses in the factor set $\Omega$. For a factor subclass $\Omega_{i}$, let $W_{i}=\left(w_{i 1}, w_{i 2}, \ldots, w_{i n_{i}}\right)$ be the weight vector of the attributes in the subclass $\Omega_{i}$ such that $\sum_{t=1}^{n_{i}} w_{i t}=1$.

Step 2: Establish the opinion set $\Theta=\left\{\varepsilon_{1}, \varepsilon_{2}, \ldots, \varepsilon_{m}\right\}$ of the alternative solution, each element is assigned with a numerical value $\alpha_{i}$.

Step 3: Assess each factor subclass $\Omega_{i}(i=1,2, \ldots, s)$ through using the single-level fuzzy synthesis evaluation method. Let the assessment matrix be $O_{i}$ and hence the fuzzy synthesis evaluation vector $B_{i}$ is given as:

$$
B_{i}=W_{i} \times O_{i}=\left(b_{i 1}, b_{i 2}, \ldots, b_{i m}\right), \quad i=1,2, \ldots, s
$$

Step 4: Calculate the assessment matrix $R$ in the factor set $\Omega=\left\{\Omega_{1}, \Omega_{2}, \ldots, \Omega_{s}\right\}$ as follows:

$$
R=\left(\begin{array}{l}
B_{1} \\
B_{2} \\
\vdots \\
B_{S}
\end{array}\right)=\left(\begin{array}{cccc}
b_{11} & b_{12} & \cdots & b_{1 m} \\
b_{21} & b_{22} & \cdots & b_{2 m} \\
\cdots & \cdots & \cdots & \cdots \\
b_{s 1} & b_{s 2} & \cdots & b_{s m}
\end{array}\right)
$$

Step 5: Calculate the fuzzy synthesis evaluation vector $B$ in terms of $B=W \times R=\left(b_{1}, b_{2}, \ldots, b_{m}\right)$.

Step 6: Determine the performance indicator of the alternative solution using maximum degree of membership method or other methods. If the maximum membership degree method is accepted, the performance 
indicator of the alternative solution is assigned with a numerical value $\alpha_{i}$, so that $b_{i}=\max \left(b_{j}\right)$

$$
P I_{1}\left(A_{l_{k}}\right)=\alpha_{i}
$$

where the alternative solution is positioned at the $i$ th evaluation grade.

\subsection{Calculation of Performance Indicator of a Design Scheme}

As indicated in the previous section, the PI of a design scheme is quantified by using fuzzy synthesis evaluation not only from technical aspects of the part design but also taking into account the evaluation grade of the part supplier. Hence, it is achieved by aggregating the evaluation grade of the supplier and PI of the alternative solution. Under a given evaluation grade of supplier and the PI of its alternative solution, the PI of its design scheme is calculated in a weighted sum way as given below:

$$
P I_{2}\left(D_{k l_{k} A_{l_{k}}}\right)=W_{\mathrm{S}} \cdot g\left(l_{k}\right)+W_{\mathrm{A}} \cdot P I_{1}\left(A_{l_{k}}\right)
$$

where $W_{\mathrm{S}}$ and $W_{\mathrm{A}}$ are weights of importance of the supplier and the alternative solution in the design scheme. Of course, some other arithmetic operators, e.g., Max operator, Min operator, Addition Operator, and Multiplication operator can also be used to obtain the performance indicator.

\section{Optimization Model for Selection of Parts Combinatorial Schemes}

During the QFD based product development process, the part deployment process is to determine product design scheme, in order to meet the product functional requirement specified in the product conceptual design phase. The purpose of the product design scheme is to determine what the composed parts are, and in what way these parts are conjunct to fulfill the functional requirement of the product. That is to say, there are twofold tasks in the product design scheme, i.e., evaluation of design scheme of part and selection of part combinatorial schemes (PCSs).

The evaluation of design scheme is to assess the part design scheme from different aspects with the measure of PI and then choose a favorable one from several competing design schemes. From the viewpoint of the part, the selected scheme is the design scheme with the highest performance indicator. However, from the product point of view, the selected scheme of a part design may not be the best design scheme of the part.
A product design scheme is a PCS that is a combinatory of selected schemes of composed parts. Hence, the selection of PCS is a process of combinatorial optimization of design schemes of each part. On the one hand, the manufacture enterprise will select the design scheme based on the PI. The higher the PI of a design scheme, the more possibility that the design scheme is selected. On the other hand, some other considerations, e.g., design budget, resources, as well as some special technical requirements, should be considered during the selection process. Thus, the selection of PCS is a decision problem that aims to determine the selected scheme of each part in the developing product in order to optimize an objective, for e.g., to maximize the overall customer satisfaction or a performance measure of the designed product under technical, resource, and financial constraints. To solve this optimization problem, a $0-1$ integer programming model has been developed through our research.

After a design scheme of a part is determined, the performance characteristic of the part related to the design scheme is determined in terms of PI. The performance of a part in a product depends completely on the design scheme selected, and hence is measured in PI. In this section, the concept of integrated performance indicator (IPI) is introduced to measure the performance of a PCS, and hence the performance characteristic of the product depends completely on the PCS. The IPI of a PCS is defined as a weighted sum of the PI of the selected scheme and each for a part in the PCS.

Given a PCS $D=\left(D_{1 l_{1} A_{l_{1}}}, D_{2 l_{2} A_{l_{2}}}, \ldots, D_{h l_{h} A_{l_{h}}}\right)$, the product design scheme is given as: part $p_{1}$ selects the $A_{l_{1}}$ th test design scheme provided by the $l_{1}$ th supplier, part $p_{2}$ selects the $A_{l_{2}}$ th design scheme provided by the $l_{2}$ th supplier, etc., and hence the part $p_{h}$ selects the $A_{l_{h}}$ th design scheme provided by the $l_{h}$ th supplier. In this case, the integrated performance indicator $I P I(D)$ of the parts combinatorial scheme $D$ is formulated as:

$$
I P I(D)=\sum_{k=1}^{h} v_{k} P I_{2}\left(D_{k l_{k} A_{l_{k}}}\right)
$$

where $v_{k}$ is the weight of the $k$ th part in the product, as given in formula (5) and it indicates the relative importance of the parts in the product.

Corresponding to each design scheme of a part, a cost for designing and manufacturing of the part in the part supplier needs to be determined. Let $c\left(D_{k l_{k} A_{l_{k}}}\right)$ be the cost for designing and manufacturing the part made from design scheme $D_{k l_{k} A_{l_{k}}}$. The cost of a part design scheme is provided from the supplier together with its technical solution when the supplier bids for the part design. However, the PI is given by the tenderee through evaluation. There are complex and nonlinear 
relationships between the PI and the cost of a design scheme of a part. Their relationships can be obtained by using some mathematical statistic tools, e.g., two variable regression analyses and dependency analysis.

Let $C(D)$ be the cost for a PCS. Assume that $C(D)$ is the sum of the costs of the design scheme selected in the PCS. Thus, given the cost vector of selected scheme of parts, $c\left(D_{1 l_{1} A_{l_{1}}}\right), c\left(D_{2 l_{2} A_{l_{2}}}\right), \ldots, c\left(D_{h l_{h} A_{l_{h}}}\right)$, the cost of the PCS $D$ is given below:

$$
C(D)=\sum_{k=1}^{h} c\left(D_{k l_{k} A_{l_{k}}}\right)
$$

Let the decision variables $x_{k l_{k} d_{l_{k}}}$ be binary variable, and satisfy $x_{k l_{k} A_{l_{k}}}=1$ when the part $p_{k}$ selects the $A_{l_{k}}$ th design scheme provided by the $l_{k}$ th supplier, otherwise $x_{k l_{k} d_{l_{k}}}=0$.

Taking into account the financial consideration in supplier involved product development, the selection of PCS with the aim of maximizing PI can be formulated as a $0-1$ integer programming model (PCS):

$$
\begin{gathered}
\max I P I(x)=\sum_{k=1}^{h} \sum_{l_{k}=1}^{n_{k}} \sum_{A_{l_{k}}=1}^{m_{l_{k}}} v_{k} \cdot P I_{2}\left(D_{k} l_{k} A_{l_{k}}\right) \cdot x_{k l_{k} A_{l_{k}}} \\
\text { s.t. } \sum_{l_{k}=1}^{n_{k}} \sum_{d_{l_{k}}=1}^{m_{l_{k}}} x_{k l_{k} d_{l_{k}}}=1 \quad \forall k=1,2, \ldots, h \\
\sum_{k=1}^{h} \sum_{l_{k=1}}^{n_{k}} \sum_{d_{l_{k}}=1}^{m_{l_{k}}} c\left(D_{k l_{k} A_{l_{k}}}\right) \cdot x_{k_{k} d_{l_{k}}} \leq C \\
x_{k l_{k} d_{l_{k}}} \in\{0,1\} \quad 1 \leq k \leq h, \quad 1 \leq l_{k} \leq n_{k}, \\
1 \leq d_{l_{k}} \leq m_{l_{k}}
\end{gathered}
$$

where $C$ is the design budget of the product pre-specified by design teams. In the PCS model, the formula (13) is the objective function to maximize IPI; Equation (14) implies that for each part of the product, only one design scheme is selected; formula (15) is the design budget constraint in the product design scheme.

The PCS model is a $0-1$ integer linear programming model which can be solved by the conventional algorithms, e.g., Branch and Bound. It can be observed from Section 2 that the weight vector of parts is obtained by mapping the weighs of customer requirements, thus the objective function of the model PCS reflects the customer requirements and subsequently coincides with the idea of QFD.

\section{An Illustrative Example}

\subsection{Background of the Illustrated Example}

A practical product design in an electric appliance manufacturing enterprise in Southwestern China is introduced in this section to illustrate the application of the proposed method. More than 20 types of electronic appliances are designed and manufactured in this electronic appliance manufacturing enterprise, where LCD and color TV are the two major product lines. During the development of a new product or product improvement in the enterprise, the supplier involvement has been considered for several years. Now the enterprise is developing a new type of LCD. The parts of this new LCD are supplied by several suppliers. According to the customer survey in the marketplace, there are more than one hundred customer requirements (CRs). Without loss of generality and for the sake of simplicity, four major CRs are selected in this example, which include good feeling in the appearance of $\mathrm{LCD}\left(\mathrm{CR}_{1}\right)$ without tired-feeling after a long time use $\left(\mathrm{CR}_{2}\right)$, facilitate in display-adjusting LCD $\left(\mathrm{CR}_{3}\right)$, and good quality of display without glint $\left(\mathrm{CR}_{4}\right)$. Their corresponding relative weights are determined as $0.1,0.2,0.1,0.6$ by the AHP method. The customer requirements and their weights are illustrated in Figure 3.

In light of the engineer experience and knowledge on this product, there are six engineering characteristics (ECs) related to the aforementioned CRs, i.e., display area $\left(\mathrm{EC}_{1}\right)$, appearance of the face frame $\left(\mathrm{EC}_{2}\right)$, maneuverability of buttons in the frame $\left(\mathrm{EC}_{3}\right)$, resolution ratio $\left(\mathrm{EC}_{4}\right)$, contrast and luminance $\left(\mathrm{EC}_{5}\right)$, and response time $\left(\mathrm{EC}_{6}\right)$. To meet the functional requirements, the engineers determine the three major parts, i.e., LCD screen $\left(\mathrm{PA}_{1}\right)$, OSD display controller $\left(\mathrm{PA}_{2}\right)$, and the frame of $\mathrm{LCD}\left(\mathrm{PA}_{3}\right)$. After quantification in terms of the information provided by the engineers, the first and second HoQs are established and illustrated in

\begin{tabular}{|l|l|l|lll|l|l|}
\cline { 2 - 9 } \multicolumn{1}{c|}{} & ECs & $\mathrm{e}_{1}$ & $\mathrm{e}_{2}$ & $\mathrm{e}_{3}$ & $\mathrm{e}_{4}$ & $\mathrm{e}_{5}$ & $\mathrm{e}_{6}$ \\
\cline { 2 - 9 } & $\mathrm{e}_{1}$ & 1 & 0.33 & 0 & 0 & 0 & 0 \\
\cline { 2 - 9 } & $\mathrm{e}_{2}$ & 0.33 & 1 & 0.56 & 0 & 0 & 0 \\
\cline { 2 - 9 } & $\mathrm{e}_{3}$ & 0 & 0.56 & 1 & 0 & 0 & 0 \\
\cline { 2 - 9 } & $\mathrm{e}_{4}$ & 0 & 0 & 0 & 1 & 0.33 & 0.33 \\
\cline { 2 - 9 } & $\mathrm{e}_{5}$ & 0 & 0 & 0 & 0.33 & 1 & 0.33 \\
\cline { 2 - 9 } & $\mathrm{e}_{6}$ & 0 & 0 & 0 & 0.33 & 0.33 & 1 \\
\hline \multirow{2}{*}{ CRss } & Weights & 0.04 & 0.101 & 0.124 & 0.229 & 0.222 & 0.287 \\
\hline req & 0.1 & 5 & 9 & 1 & 0 & 0 & 0 \\
\hline req2 & 0.2 & 1 & 0 & 0 & 5 & 5 & 0 \\
\hline req3 & 0.1 & 0 & 0 & 9 & 0 & 0 & 0 \\
\hline req4 & 0.6 & 0 & 0 & 3 & 5 & 3 & 9 \\
\hline
\end{tabular}

Figure 3. $\mathrm{HoQ}_{1}$ of product planning. 
Figures 3 and 4 , where the $\mathrm{req}_{i}$ and $\mathrm{e}_{j}$ denote the CRs and ECs respectively. In Figure 3, the relationships between CRs and ECs are quantified by scale 1-3-5-9 and the correlations among ECs are quantified in a normalized way. The relationship matrix between ECs and PAs and the correlations among PAs in Figure 4 are explained in a similar way.

The weights of the ECs indicated in the Figure 3 and the weights of the parts shown in Figure 4 are obtained in light of the formulae (3) and (5) respectively, hence

$$
\begin{aligned}
& U^{*}=(0.04,0.101,0.124,0.229,0.222,0.287), \\
& V^{*}=(0.457,0.270,0.273)
\end{aligned}
$$

During the design of LCD screen, OSD display screen and frame of LCD, there are several suppliers. Each provides more than one design scheme. For simplicity, assume that three suppliers of LCD screen denoted by $\mathrm{S}_{11}, \mathrm{~S}_{12}, \mathrm{~S}_{13}$ provide one, two and three design schemes of LCD screen respectively. There is only one supplier of the OSD display controller $\mathrm{S}_{21}$ and it provides five alternative design solutions for OSD display screen.

\begin{tabular}{|l|l|l|l|l|}
\cline { 2 - 5 } \multicolumn{1}{c|}{} & $P A_{s}$ & $\mathrm{PA}_{1}$ & $\mathrm{PA}_{2}$ & $\mathrm{PA}_{3}$ \\
\cline { 2 - 5 } \multicolumn{1}{c|}{} & $\mathrm{PA}_{1}$ & 1 & 0.33 & 0.33 \\
\cline { 2 - 5 } & $\mathrm{PA}_{2}$ & 0.33 & 1 & 0.56 \\
\cline { 2 - 5 } & $\mathrm{PA}_{3}$ & 0.33 & 0.56 & 1 \\
\hline \multirow{2}{*}{$E C s$} & Weights & 0.457 & 0.270 & 0.273 \\
\hline $\mathrm{e}_{1}$ & 0.040 & 9 & 3 & 9 \\
\hline $\mathrm{e}_{2}$ & 0.101 & 0 & 3 & 9 \\
\hline $\mathrm{e}_{3}$ & 0.124 & 0 & 9 & 3 \\
\hline $\mathrm{e}_{4}$ & 0.229 & 9 & 0 & 0 \\
\hline $\mathrm{e}_{5}$ & 0.222 & 9 & 0 & 0 \\
\hline$e_{6}$ & 0.287 & 9 & 0 & 0 \\
\hline
\end{tabular}

Figure 4. $\mathrm{HoQ}_{2}$ of parts product planning.
Two suppliers of the frame of LCD are denoted by $S_{31}$, $\mathrm{S}_{32}$, and each provides two alternative design solutions for the frame of LCD. The relationships between parts, supplier, and alternative solutions, as well as the costs of the design schemes provided by the suppliers, are presented in the first four columns in Table 1.

\subsection{Evaluation of the Supplier and Design Scheme}

During the assessment of supplier, the first supplier of the LCD screen, $\mathrm{S}_{11}$, is illustrated as an example. Four evaluation classes, excellent, good, normal, and bad are selected; their corresponding numerical values are given as $0.9,0.7,0.5$, and 0.3 respectively. Five influencing factors including price, quality, core design ability, credit standing level, and supply capacity are selected and their weights are given as $0.2,0.4,0.2,0.1$, and 0.1 respectively. During the assessment, the members from the engineering department and the procurement department evaluate the suppliers from each attribute (e.g., price) separately. Thereby the assessment vector (e.g., 0.3, 0.8, 0.4, and 0.1) and subsequently the assessment matrix can be obtained. Let the assessment matrix of the supplier obtained in this way be:

$$
\mathbf{O}=\left(\begin{array}{llll}
0.3 & 0.8 & 0.4 & 0.1 \\
0.2 & 0.7 & 0.4 & 0.1 \\
0.7 & 0.5 & 0.3 & 0.1 \\
0.2 & 0.8 & 0.4 & 0.1 \\
0.3 & 0.4 & 0.6 & 0.4
\end{array}\right)
$$

where the second row to the last row denote the assessment vectors of the quality, core design ability,

\begin{tabular}{|c|c|c|c|c|c|c|}
\hline Parts & Suppliers & $\begin{array}{c}\text { Alternative } \\
\text { solution (AS) }\end{array}$ & $\begin{array}{l}\text { Cost of design } \\
\text { scheme }(* 100)\end{array}$ & $\begin{array}{l}\text { Evaluation of } \\
\text { supplier } g_{k}\left(S_{k}\right)\end{array}$ & $\begin{array}{c}\mathrm{PI} \text { of } \\
\mathrm{AS}\left(\mathrm{PI}_{1}\right)\end{array}$ & $\begin{array}{l}\mathrm{PI} \text { of design } \\
\text { scheme }\left(\mathrm{PI}_{2}\right)\end{array}$ \\
\hline \multirow[t]{6}{*}{ LCD screen } & $\mathrm{S}_{11}$ & $D_{111}$ & 18.9 & 0.7 & 0.7 & 0.70 \\
\hline & \multirow[t]{2}{*}{$\mathrm{S}_{12}$} & $D_{121}$ & 19.2 & \multirow[t]{2}{*}{0.9} & 0.9 & 0.90 \\
\hline & & $D_{122}$ & 19.0 & & 0.7 & 0.76 \\
\hline & \multirow[t]{3}{*}{$\mathrm{S}_{13}$} & $D_{131}$ & 19.8 & \multirow[t]{3}{*}{0.7} & 0.9 & 0.84 \\
\hline & & $D_{132}$ & 19.2 & & 0.7 & 0.70 \\
\hline & & $D_{133}$ & 18.7 & & 0.5 & 0.56 \\
\hline \multirow[t]{5}{*}{ OSD display controller } & \multirow[t]{5}{*}{$\mathrm{S}_{21}$} & $D_{211}$ & 2.4 & \multirow[t]{5}{*}{0.9} & 0.9 & 0.90 \\
\hline & & $D_{212}$ & 1.9 & & 0.7 & 0.76 \\
\hline & & $\mathrm{D}_{213}$ & 1.6 & & 0.5 & 0.62 \\
\hline & & $D_{214}$ & 1.5 & & 0.5 & 0.62 \\
\hline & & $D_{215}$ & 1.9 & & 0.7 & 0.76 \\
\hline \multirow[t]{4}{*}{ LCD frame } & \multirow[t]{2}{*}{$\mathrm{S}_{31}$} & $D_{311}$ & 0.8 & \multirow[t]{2}{*}{0.7} & 0.9 & 0.84 \\
\hline & & $D_{312}$ & 0.6 & & 0.7 & 0.70 \\
\hline & \multirow[t]{2}{*}{$\mathrm{S}_{32}$} & $D_{321}$ & 0.9 & \multirow[t]{2}{*}{0.7} & 0.9 & 0.84 \\
\hline & & $D_{322}$ & 0.5 & & 0.7 & 0.70 \\
\hline
\end{tabular}
credit standing level, and supply capacity respectively.

Table 1. Evaluation results of the supplier, alternative solution, and design scheme. 
Using the formula $B=W \times \boldsymbol{O}$, the fuzzy synthesis evaluation vector $\boldsymbol{B}=(0.27,0.56,0.48$, and 0.19$)$ can be obtained. Because $\max \left(b_{j}\right)=b_{2}=0.56$, the evaluation class of the supplier $S_{11}$ is a second class, i.e., good, using the maximum degree of membership method and its numerical value is 0.7 . Thus, the numerical value of the fuzzy synthesis evaluation of the supplier $S_{11}$ is given as $g_{1}\left(s_{11}\right)=0.7$.

The evaluation of the alternative solution and design scheme are illustrated as follows with the example of the first alternative solution of the LCD screen provided by the first supplier.

During the assessment of the alternative solutions of the design of OSD display controller, the following 11 attributes are considered: the way of luminescence $u_{1}$, the working temperature $\mathrm{u}_{2}$, the way of interface $\mathrm{u}_{3}$, the display acreage $\mathrm{u}_{4}$, the scope of visual angle $\mathrm{u}_{5}$, the contrast and luminance $\mathrm{u}_{6}$, the response time $\mathrm{u}_{7}$, the display pigment $\mathrm{u}_{8}$, resolution ratio $\mathrm{u}_{9}$, refurbish rate $\mathrm{u}_{10}$, and dead point $\mathrm{u}_{11}$. These attributes are categorized into subclasses, i.e., Customer (CT), Examiner (EX), and Expert (EP) from the perspective of conductor of evaluations. The first three attributes belong to the CT subclass. The attributes numbered from 4-7 are in EX subclass, and the others are in EP subclass. For example, an alternative solution is evaluated from the customer's perspective under consideration of the attributes of $\mathrm{u}_{1}, \mathrm{u}_{2}$, and $\mathrm{u}_{3}$. The weights for these subclasses are given as $0.3,0.25$, and 0.45 . The weight vectors of these attributes in the CT, EX, and EP subclasses are given as $W_{1}, W_{2}$ and $W_{3}$ respectively, they are:

$$
\begin{aligned}
& W_{1}=(0.3,0.25,0.45) \quad W_{2}=(0.25,0.25,0.25,0.25) \\
& W_{3}=(0.3,0.3,0.20,0.20) .
\end{aligned}
$$

The set of evaluation grade of an alternation solution is given in four classes: $\varepsilon_{1}$ (first-class), $\varepsilon_{2}$ (second-class), $\varepsilon_{2}$ (inferior) and $\varepsilon_{4}$ (waster), i.e., $\Theta=\left\{\varepsilon_{1}, \varepsilon_{2}, \varepsilon_{3}, \varepsilon_{4}\right\}$.

For the alternative solution $D_{111}$, the assessment matrixes of Customers, Examiners and Experts denoted by $\mathbf{R}_{1}, \mathbf{R}_{2}$ and $\mathbf{R}_{3}$ respectively are given as follows:

$$
\begin{aligned}
& \mathbf{R}_{1}=\left(\begin{array}{cccc}
0.36 & 0.24 & 0.13 & 0.27 \\
0.20 & 0.32 & 0.25 & 0.23 \\
0.60 & 0.30 & 0.10 & 0
\end{array}\right), \\
& \mathbf{R}_{2}=\left(\begin{array}{llll}
0.30 & 0.28 & 0.24 & 0.18 \\
0.26 & 0.36 & 0.12 & 0.20 \\
0.35 & 0.30 & 0.20 & 0.15 \\
0.22 & 0.42 & 0.16 & 0.10
\end{array}\right),
\end{aligned}
$$

$$
\mathbf{R}_{3}=\left(\begin{array}{cccc}
0.24 & 0.56 & 0.10 & 0.10 \\
0.34 & 0.48 & 0.15 & 0.03 \\
0.38 & 0.24 & 0.08 & 0.20 \\
0.24 & 0.28 & 0.30 & 0.18
\end{array}\right)
$$

By multiplying the weight vector and assessment matrix, the corresponding assessment vectors under subclasses CT, ET, and EP denoted by $\boldsymbol{B}_{1}, \boldsymbol{B}_{2}$, and $\boldsymbol{B}_{3}$ are respectively obtained as follows:

$$
\begin{aligned}
& \boldsymbol{B}_{1}=(0.43,0.29,0.14,0.14), \quad \boldsymbol{B}_{2}=(0.28,0.34,0.18,0.16), \\
& \boldsymbol{B}_{3}=(0.30,0.42,0.15,0.12)
\end{aligned}
$$

The assessment vector of multi-class fuzzy synthesis evaluation is finally given by

$$
\begin{aligned}
B & =W \times\left(\begin{array}{l}
B_{1} \\
B_{2} \\
B_{3}
\end{array}\right) \\
& =(0.30,0.25,0.45)\left(\begin{array}{llll}
0.43 & 0.29 & 0.14 & 0.14 \\
0.28 & 0.34 & 0.18 & 0.16 \\
0.30 & 0.42 & 0.15 & 0.12
\end{array}\right) \\
& =(0.33,0.36,0.15,0.14) .
\end{aligned}
$$

Obviously, the alternative solution, $D_{111}$, is evaluated as the second class (good), and hence the performance indicator of the alternative solution is $P I_{1}\left(D_{111}\right)=0.7$. Thus, by aggregating the evaluation grade of the supplier and the alternative solution using Weight Sum Operator, the PI of the first design scheme for LCD screen provided by the first supplier is,

$$
\begin{aligned}
P I_{2}\left(D_{111}\right) & =0.3 \times g_{1}\left(s_{11}\right)+0.7 \times P I_{1}\left(D_{111}\right) \\
& =0.3 \times 0.7+0.7 \times 0.7=0.70
\end{aligned}
$$

where, the supplier and the alternative solution are given weights 0.3 and 0.7 respectively, when evaluating a design scheme.

Likewise, the other suppliers, alternative solution, and design schemes are evaluated and the results are given in the last three columns in Table 1.

\subsection{Selection of Parts Combinatorial Scheme (PCS)}

As indicated in Table 2, there are six design schemes from three suppliers for LCD screen design, five design 
Table 2. Part combinatorial schemes vary with design budget and comparison with competitive companies.

\begin{tabular}{lccc}
\hline Design budget & $\begin{array}{c}\text { Part combinatorial } \\
\text { scheme (PCS) }\end{array}$ & $\begin{array}{c}\text { Costs for } \\
\text { the PCS (*100RMB) }\end{array}$ & $\begin{array}{c}\text { Integrated performance } \\
\text { indicator of PCS }\end{array}$ \\
\hline 21.0 & $\left(D_{122}, D_{214}, D_{322}\right)$ & 21.0 & 0.7088667 \\
22.0 & $\left(D_{111}, D_{212}, D_{311}\right)$ & 0.84582 \\
23.0 & $\left(D_{121}, D_{211}, D_{311}\right)$ & 22.0 & 0.88362 \\
24.0 & $\left(D_{121}, D_{211}, D_{311}\right)$ & 23.0 & 0.88362 \\
24.5 & $\left(D_{121}, D_{211}, D_{311}\right)$ & 23.0 & 0.88362 \\
25.5 & $\left(D_{121}, D_{211}, D_{311}\right)$ & 23.0 & 0.88362 \\
Competitive company LCD & & 23.0 & Costs for the \\
& & LCD (*100RMB) & Integrated performance \\
Company 1 & $\mathrm{N} / \mathrm{A}$ & 24.5 & indicator of the LCD \\
Company 2 & $\mathrm{N} / \mathrm{A}$ & 25.5 & 0.70516 \\
Company 3 & $\mathrm{N} / \mathrm{A}$ & 22.0 & 0.75442 \\
\hline
\end{tabular}

Table 3. The part combinatorial scheme of the LCD example using the proposed model.

\begin{tabular}{|c|c|c|c|c|c|c|c|c|c|c|c|c|c|c|c|}
\hline Max S & $x_{111}$ & $x_{121}$ & $x_{122}$ & $x_{131}$ & $x_{132}$ & $x_{133}$ & $x_{211}$ & $x_{212}$ & $x_{213}$ & $x_{214}$ & $x_{215}$ & $x_{311}$ & $x_{312}$ & $x_{321}$ & $x_{322}$ \\
\hline 0.84582 & 1 & 0 & 0 & 0 & 0 & 0 & 0 & 1 & 0 & 0 & 0 & 1 & 0 & 0 & 0 \\
\hline
\end{tabular}

schemes for OSD display controller, and four design schemes for LCD frame from two suppliers. In total, there are amounts of 120 alternations for PCS for a LCD. Given a design cost budget of $22(* 100)$ RMB, using the tool software QSB, one can obtain the optimal part combinatorial design as shown in Table 3.

From Table 3, one can find that the parts combinatorial scheme is $\left(D_{111}, D_{212}, D_{311}\right)$ with the IPI being 0.84582 . The PCS and its IPI under different values of design budget are shown in the first seven rows in Table 3. The costs of the LCD of the competitive companies and their IPI are presented in the last four rows in Table 3 as a comparison with the developing LCD. From Table 3, one can find that the IPI of the PCS presented in the last column increases with the design budget, however, the largest amount of costs for the design is 2300 . That is to say, in light of the part combinatorial scheme, the maximum IPI can be achieved at 0.88362 when the cost of $2300 \mathrm{RMB}$ will be consumed even though the design budget is beyond 2300RMB. It also shows that the developing LCD made from the PCS performs better than the ones from competitive companies, even though they charge more cost than the developing one.

\section{Conclusions}

By introducing the concepts of performance indicator and integrated performance indicators, a two-layer fuzzy synthesis evaluation method is applied to assess the part design scheme in supplier involved new product development process. Combining the information of HoQ and evaluation results of the part design scheme into the selection of part design schemes, and taking into account the design budget, a $0-1$ integer programming model is developed for selection of part combinatorial schemes in supplier involved part deployment processes. Distinguished from other approaches, this approach considers the involvement of part-suppliers during the conceptual design process and it combines the evaluation and optimization for part design scheme selection. By embedding the proposed method, a software system of evaluation and selection of supplier involved part design (ESSIPD) is now being developed to facilitate the application of the proposed method in practical part design decision.

\section{Acknowledgments}

The paper is financially supported by the Natural Science Foundation of China (NSFC 70471028, 70431003), the Key Scientific Research Program (104064) of Ministry of Education (MOE), the Excellent Youth Teacher Program (EYTP), the Program for New Century Excellent Talents in University (NCET-04-0280) of MOE of China and Key Laboratory of Process Industrial Automation of MOE in Northeastern University, and NSERC Strategic 
Research Program and NSERC Discovery Grant of Canada.

\section{References}

1. Akao, Y. (1990). Quality Function Deployment: Integrating Customer Requirements into Product Design, Productivity Press, Cambridge, MA.

2. Armacost, R.L. (1994). An AHP Framework for Prioritizing Customer Requirements in QFD: An Industrial Applications, IIE Transactions, 26(4): 72-79.

3. Bidault, F., Despres, C. and Butler, C. (1998). The Drivers of Cooperation between Buyers and Suppliers for Product Innovation, Research Policy, 26(7-8): 719-732.

4. Chan, L.K. and Wu, M.L. (2002). Quality Function Deployment: A literature review, European Journal of Operations Research, 143(3): 463-497.

5. Chen, Y.Z., Tang, J.F., Ren, Z., et al. (2003). A Design Scheme Selection Program Model Based on House of Quality, Chinese Journal of Computer Integrated Manufacture Systems-CIMS, 9(2): 127-131.

6. Caputo, M. and Zirpoli, F. (2002). Supplier Involvement in Automotive Component Design: Outsourcing Strategies and Supply Chain Management, Int. J. Technol. Manage., 23(1-3): 129-154.

7. Dre, C., Jayanth, J. and Shawnee, K.V. (2000). The Ability to Minimize the Timing of New Product Development and Introduction: An Examination of Antecedent Factors in the North American Automobile Supplier Industry, Journal of Product Innovation Management, 17(1): 24-40.

8. Fung, R.Y.K., Tang, J.F., Tu, Y.L. and Wang, D. (2002). Product Design Resources Optimization using a Non-linear Fuzzy Quality Function Deployment Model, International Journal of Production Research, 40(3): 585-599.

9. Fung, R.Y.K., Tang, J.F., Tu, Y.L. and Chen, Y.Z. (2003). Modeling of Quality Function Deployment Planning with Resource Allocation, Research in Engineering Design with Applications, 14(4): 247-255.

10. Gui, Z., Lin, Z. and Yan, M.S. (2003). Fuzzy Integer Planning for Parts Selection in Product Development, Chinese Journal of Machine Tool and Hydraulic Pressure, 10(1): 23-28.

11. Huang, G.Q., Zhao, J.B. and Mak, K.L. (2003). Early Supplier Involvement in New Product Development with WeBid: A Case Study on Video Conferencing System, Journal of Computing and Information Science in Engineering, 3(4): 363-365.

12. Hauser, J.R. and Clausing, D. (1988). The House of Quality, Harvard Business Review, 66(3): 63-73.

13. Herrmann, A., Huber, F. and Braunstein, C. (2000). Market-driven Product and Service Design: Bridging the Gap between Customer Needs, Quality Management, and Customer Satisfaction, International Journal of Production Economics, 66(1): 77-96.

14. Holmenand, E. and Kristensen, P.S. (1998). Supplier Roles in Product Development: Interaction versus Task Partitioning, European Journal of Purchasing \& Supply Management, 4(2-3): 185-193.
15. Iranmanesh, S.H., Thomson, V. and Salimi, M.H. (2005). Design Parameter Estimation using a Modified QFD Method to Improve Customer Perception, Journal of Concurrent Engineering: Research and Applications, 13(1): $57-67$.

16. Kim, K.J., Moskowitz, H., Dhingra, A. and Evans, G. (2000). Fuzzy Multi-criteria Models for Quality Function Deployment, European Journal of Operational Research, 121(3): 504-518.

17. LaBahn, D.W. and Krapfel, R. (2000). Early Supplier Involvement in Customer New Product Development; A Contingency Model of Component Supplier, Intentional Journal of Business Research, 47(3): 173-190.

18. Maffinand, D. and Braiden, P. (2001). Manufacturing and Supplier Roles in Product Development, International Journal of Production Economics, 69(2): 205-213.

19. Pahl, G. and Beitz, W. (1998). Engineering Design: A Systematic Approach, London: The Design Council.

20. Prasad, B. (1998). Review of QFD and Related Deployment Techniques, Journal of Manufacturing Systems, 17(3): 221-234.

21. Prasad, B. (2000). A Concurrent Function Deployment Technique for a Workgroup-based Engineering Design Process, Journal of Engineering Design, 11(2): 103-119.

22. Ragatz, G.L., Handfield, Robert B. and Petersen, Kenneth J. (2002). Benefits Associated with Supplier Integration into New Product Development under Conditions of Technology Uncertainty, Journal of Business Research, 55(5): 389-400.

23. Shen, X.X., Tan, K.C. and Xie, M. (2000). An Integrated Approach to Innovative Product Development using Kino's Model and QFD, European Journal of Innovation Management, 3(2): 91-99.

24. Sobrero, M. and Roberts, E.B. (2002). Strategic Management of Supplier-manufacturer Relations in New Product Development, Research Policy, 31(1): 159-182.

25. Tang, J.F., Fung, R.Y.K., Xu, B. and Wang, D. (2002). A New Approach to Quality Function Deployment Planning with Financial Consideration, Computers \& Operations Research, 29(11): 1447-1463.

26. Tang, J.F., Chen, Y. and Dong, Y. (2004). An Integrated Product Development Model based on Quality Function Deployment with Customer and Supplier Involvement, The Asia Journal on Quality, 5(4): 50-60.

27. Toni, D.A. and Nassimbeni, G. (2001). A Method for the Evaluation of Suppliers' Co-design Effort, International Journal of Production Economics, 72(2): 169-180.

28. Vairaktarakis, George L. (1999). Optimization Tools for Design and Marketing of New/improved Products using the House of Quality, Journal of Operations Management, 17(6): 645-663.

29. Wasserman, G.S. (1993). On How to Prioritize Design Requirements During the QFD Planning Process, IIE Transactions, 25(3): 59-65.

30. Wynstra, F., Axelsson, B. and Weele, A. (2000). Driving and Enabling Factors for Purchasing Involvement in Product Development, European Journal of Purchasing \& Supply Management, 6(2): 129-141.

31. Wynstra, F., Weele, A. and Weggemann, M. (2001). Managing Supplier Involvement in Product Development: Three Critical Issues, European Management Journal, 19(2): 157-167. 
Jiafu Tang

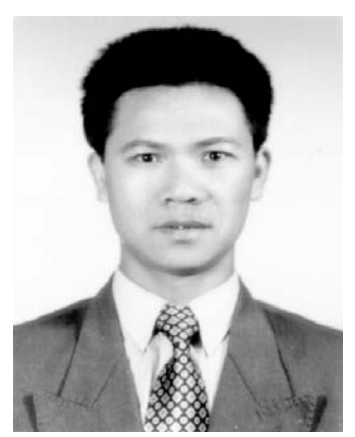

journals e.g., IEEE Trans on SMC, Int $J$ of Production Research, Fuzzy Sets and Systems, Production Planning and Control, Int $\mathbf{J}$ of Advanced Manufacturing Technologies, Computers \& Operations Research, Computers \& Mathematics with
Applications, etc. His research interests include fuzzy modeling and optimization, supply chain planning and logistics management, and supplier involved product development.

\section{Yan-E Zhang}

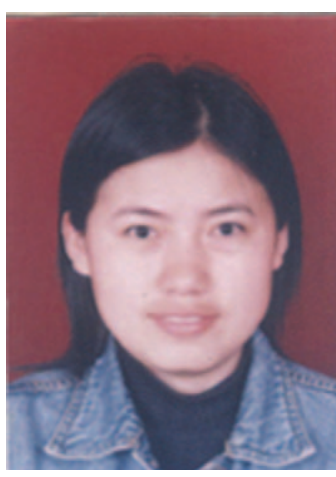

Yan-E Zhang received the Master of Science degree and Bachelor degree both from Northeastern University, Shenyang, China in 2005 and 2002 respectively. She works currently at WISDRI Engineering \& Research Incorporation Limited, Wuhan, China. She is interested in the research of optimization of product design and system design of industrial automation. 